\title{
TRABAJO, FAMILIA Y PREVISIÓN SOCIAL EN EL PRIMER FRANQUISMO: EL PLUS DE CARGAS FAMILIARES
}

\author{
Dr. Guillermo García González \\ Profesor Titular de Derecho del Trabajo y de la Seguridad Social \\ Universidad Internacional de La Rioja
}

\begin{abstract}
El presente artículo analiza desde una perspectiva histórico-jurídica la etiología y dinámica del plus de cargas familiares o plus familiar, herramienta de previsión social vigente en el primer franquismo, y que constituye un ejemplo paradigmático de la instrumentalización de las instituciones de seguridad social al servicio de fines políticos y de una concreta ideología. El estudio examina las dos décadas de vigencia del plus familiar, haciendo especial énfasis en sus fundamentos ideológicos y en su controvertida naturaleza jurídica.
\end{abstract}

This article analyses from a historical-legal perspective the etiology and dynamics of the family responsibilities bonus (also known as family bonus) in force during the first Francoism. It constitutes a prime example of the instrumentalization of the Social Security institutions acting at the service of political ends and of a specific ideology. This research examines two decades in which this family bonus was in force, emphasizing on its ideological foundations and its controversial legal nature.

Title: Employment, family and social welfare during the first Francoism: family responsibilities bonus

Palabras clave: familia, franquismo, plus familiar, previsión social, seguridad social Keywords: family, Francoism, family bonus, social welfare, social security

IUSLabor 3/2021, ISSN 1699-2938, p. 206-241

DOI. 10.31009/IUSLabor.2021.i03.08

Fecha envío: 24.9.2021 | Fecha aceptación: 7.10.2021 


\section{Sumario}

1. Introducción

2. Fundamentos ideológicos de la protección de la familia en el primer franquismo

3. La institucionalización de la protección familiar en el primer franquismo: alcance y dinámica del plus familiar

3.1. Antecedentes, origen y desarrollo del plus familiar

3.2. Financiación y administración del plus familiar

3.3. Ámbito de aplicación

3.4. Beneficiarios

3.5. Reparto del plus: el sistema de puntos

4. La compleja naturaleza jurídica del plus familiar

5. A modo de epílogo: cenit y ocaso del plus familiar

6. Bibliografía 


\section{Introducción}

Como cualquier rama del ordenamiento jurídico, el derecho de la seguridad social en su conformación actual es el fruto de un largo y costoso proceso de sedimentación normativo e institucional. A principios del siglo XX, la incipiente legislación social española comienza a dar los primeros pasos hacía la institucionalización de la previsión social, entendida como un conjunto asistemático de diversos seguros sociales independientes entre sí1. A partir de entonces, y a través de la técnica de los seguros sociales, se fue conformando un disperso sistema protector de las distintas contingencias a las que se veía sometida la clase obrera.

Entre las situaciones merecedoras de tutela, pronto se visibilizó la conveniencia de proteger al obrero frente a las cargas familiares derivadas de su situación personal. Ante la insuficiencia del derecho civil para hacer frente a las necesidades familiares -a través del socorro mutuo entre cónyuges y el derecho a alimentos entre parientes, principalmente- el intervencionismo estatal se ve obligado a ampliar los ámbitos de solidaridad más allá de los estrictamente familiares, pasando la familia de ser una cuestión que solo afecta a un individuo a ser objeto de compromiso por parte de la sociedad. Se inicia así un tránsito que desplaza a la familia de lo individual a lo social, y se insertan los deberes familiares -esencialmente del cabeza de familia, varón y obreroen el ámbito protector de la previsión social².

\footnotetext{
${ }^{1}$ Alonso Olea, Manuel, Instituciones de Seguridad Social, Madrid, Civitas, 1983, 9a ed., p. 22. La doctrina mayoritaria sitúa el inicio de los seguros sociales en España en la Ley de Accidentes del Trabajo de 30 de enero de 1900 (Gaceta de Madrid, 31 de enero). Desde ese momento y hasta 1919, el incipiente desarrollo de la seguridad social en nuestro país se articula en torno a los seguros sociales voluntarios. Es a partir de 1919 cuando comienza una nueva fase en el desarrollo histórico de la seguridad social en nuestro país: los seguros sociales obligatorios. Vid. Comín y Comín, Francisco, "Las fases históricas de la Seguridad Social en la España del siglo XX", en Tortuero PlaZA, José Luís (Director), Cien años de Protección Social en España, Ministerio de Trabajo y Asuntos Sociales, Madrid, 2007, p. 652 y ss. Cfr. Alonso OlEA, Manuel, "La Seguridad Social: presente, pasado y futuro", en GonZAlo GonZÁlez, Bernardo y NogueIRa Gustavino, Magdalena (Directores), Cien Años de Seguridad Social, UNED y Fraternidad Muprespa, Madrid, 2000, p. 177. El autor emplea la misma periodificación, denominado a la primera etapa (1900-1919) episodios iniciales, y, a la segunda, con comienzo en 1919, ampliación de riesgos cubiertos. Desde otra perspectiva, se ha considerado al Real Decreto de 29 de julio de 1917, por el que se convoca la Conferencia de Seguros Sociales a celebrar en Madrid entre el 24 y el 31 de octubre de 1917 (Gaceta de Madrid, 31 de julio), como el inicio de la etapa de previsión social en España; y ello, sin perjuicio de que la implantación de los seguros sociales en nuestro país sea el "resultado natural de la evolución de una política previa de fomento del aseguramiento facultativo o voluntario frente a riesgos profesionales y comunes, en funcionamiento ya desde el comienzo mismo del siglo XX". MARTínEZ GIRÓN, Jesús, "La etapa de previsión social en España", Anuario da Facultade de Dereito da Universidade da Coruña, $\mathrm{n}^{\circ}$ 5, 2001, p. 431.

2 Almansa PAStor, José Manuel, Derecho de la Seguridad Social, Madrid, Tecnos, 1973, p. 334-335.
} 
En España, la familia como objeto de protección por la seguridad social surge ligada a la condición de asalariado del cabeza de familia, tradicionalmente varón. Tiene la primera manifestación específica y autónoma en el Real Decreto-Ley de 21 de junio de $1926^{3}$, relativo a los subsidios de familias numerosas de la clase obrera, norma dictada en plena dictadura del General Primo de Rivera ${ }^{4}$. Prescindiendo de esta limitada manifestación previsional, la protección a la familia por técnicas de seguridad social se desarrolla y adquiere su mayor protagonismo durante el régimen franquistaespecialmente en sus primeras décadas- y se inserta en la tendencia expansiva y descoordinada que en ese periodo viven los seguros sociales.

En los primeros años de la dictadura franquista se desarrolla un modelo profesional de seguros sociales asistemático y sin ningún tipo de vertebración, que es instrumentalizado por el régimen con fines propagandísticos ${ }^{5}$; esta situación se inicia en 1938, aún vigente la guerra civil, y perdurará hasta la aprobación de la Ley 193/1963, de 28 de diciembre, sobre Bases de la Seguridad Social ${ }^{6}$. Pese a que la realización práctica de los seguros sociales durante este periodo dista mucho de la visión que se refleja en los discursos oficialistas, las aportaciones normativas que al campo de la seguridad social se diseñan e implementan durante el primer franquismo pueden ser consideradas como unas de las de mayor trascendencia en lo que al derecho del trabajo lato sensu se refiere $^{7}$. La extensa producción normativa de este periodo se debe entender partiendo del nulo juego que en el mismo desempeñan la autonomía colectiva e individual en la regulación de las condiciones de trabajo. La supresión de los derechos de autorregulación y autodefensa de trabajadores y empresarios por el régimen franquista

\footnotetext{
${ }^{3}$ Gaceta de Madrid, 22 de junio de 1926.

${ }^{4}$ Previamente a esta disposición, la legislación sobre accidentes de trabajo que se inicia en España con la Ley de Accidentes del Trabajo de 30 de enero de 1900, expande su campo de protección a la familia del obrero accidentado. Esta extensión resulta lógica, teniendo en cuenta que el modelo de familia obrera de la época era una familia numerosa, con dependencia económica absoluta respecto al trabajador varón. Por ello, cualquier incapacidad de este suponía una situación de necesidad para toda la familia. Estas primeras manifestaciones de protección familiar se asociaban siempre con otras contingencias no orientándose directa y autónomamente a la familia. En este sentido, vid. BuENAGA CEBALlos, Óscar, La familia y la Seguridad Social, Madrid, Dykinson, 2014, p. 96 y ss. Sobre la distinción entre prestaciones familiares directas e indirectas, vid. GORELLI HERNÁNDEZ, Juan, "Seguridad Social y protección familiar", Revista del Ministerio de Trabajo y Asuntos Sociales, $\mathrm{n}^{\circ}$ 59, 2005, p. 52 y ss.

5 Comín y Comín, Francisco, "Las fases históricas de la Seguridad Social en España (1900-2000)", Revista de Historia de la Economía y de la Empresa, nº 4, 2007, p. 70 y 71.

${ }^{6}$ BOE, 30 de diciembre de 1963. La exposición de motivos de esta norma subrayaba que su finalidad era "operar el tránsito de un conjunto de Seguros Sociales a un sistema de Seguridad Social". Vid. BLASCO LAHOZ, José Francisco y LóPEZ Gandía, Juan, Curso de Seguridad Social, Valencia, Tirant lo Blanch, 2016, $6^{\mathrm{a}}$ ed., p. 41.

7 DE LA VILLA GIL, Luis Enrique, La formación histórica del Derecho Español del Trabajo, Granada Comares, 2003, p. 510 y 511.
} 
tiene como contrapartida la ampliación espectacular de la protección social, perfeccionando y extendiendo "con amplitud inédita la regulación normativa" y generando un "desarrollo científico sin precedentes del Derecho del Trabajo y de la Seguridad Social" 8 .

Entre todos los seguros sociales de base profesional que se implementan en dicho periodo, la emergencia y consolidación de la protección social de la familia en el primer franquismo parece lógica si se tiene en cuenta que, entre los principios ideológicos que presidían el régimen totalitario, la familia constituía un elemento esencial para articular su concreto modelo político y social. Este interés por la familia obedecía, sin lugar a dudas, al papel que los cambios en la regulación de la institución familiar tienen como símbolo de ruptura con el pasado y como cimientos de la construcción de una nueva realidad $^{9}$. Guiados por este deseo disruptivo, y con el fin de construir una nueva realidad sociopolítica, el franquismo proclama a la familia como la "célula primaria natural y fundamento de la Sociedad", al mismo tiempo que la reconoce como una "institución moral dotada de derecho inalienable superior a toda ley positiva"10. Por ello, es obligación del Estado proporcionar "el amparo, vigilancia y protección a la familia para que cumpla sus altos destinos históricos, siendo relicario de fe, de patriotismo y de voluntad de grandeza" 11 . Será esta concepción tradicional de la familia la que presidirá todo el sistema protector diseñado por la primera legislación franquista para proteger las contingencias familiares. De este modo, la normativa de seguridad social se convierte en un instrumento más de reafirmación de los principios que impulsan el nuevo régimen político y que se pueden sintetizar en la supremacía del Estado en detrimento de las libertades individuales y colectivas. Se persigue, en última instancia, invadir y controlar el entorno familiar, "la institución de la familia en sí misma (...) como órgano corporativo, como célula primaria de la sociedad orgánica" 12 .

La protección familiar otorgada por los seguros sociales en el primer franquismo se ancla en dos instituciones fundamentales: el subsidio familiar y el plus de cargas familiares o plus familiar ${ }^{13}$. La incipiente implantación del subsidio familiar por el

\footnotetext{
8 DE LA VILla GIL, Luis Enrique, “El Derecho del Trabajo en España a partir de la transición”, Revista de Trabajo y Seguridad Social, no 238, 2003, p. 41.

9 IGLESIAS DE Ussel, Julio, “La familia y el cambio político en España”, Revista de Estudios Políticos, $\mathrm{n}^{\circ}$ 67, 1990, p. 235.

10 Declaración XII.3 Decreto 9 de marzo de 1938, por el que se aprueba el Fuero del Trabajo (BOE, 10 de marzo).

11 Preámbulo Ley 1 de agosto de 1941, de protección a las familias numerosas (BOE, 13 de septiembre).

12 CARASA Soto, Pedro, "La revolución nacional-asistencial durante el primer franquismo (1936-1940)", Historia Contemporánea, no 16, 1997, p. 114 y 115.

13 El plus de cargas familiares pasará a denominarse plus familiar a partir de la Orden de 16 de octubre de
} 
régimen totalitario en 1938, en plena guerra civil, se vio complementada por la creación del plus de cargas familiares, primero, en el marco de las reglamentaciones nacionales de trabajo, y, posteriormente, mediante su regulación normativa con pretendida vocación de generalidad. El plus se origina inicialmente como una institución subalterna -complementa el raquítico subsidio familiar- transitoria -su pervivencia inicialmente se anuda a la excepcional situación económica de postguerra- y extraordinaria, si se compara con el carácter ordinario del subsidio familiar. Así, el plus se crea "para solucionar durante esta época anormal de carestía de vida (...) la situación deficitaria de la familia española"14. A pesar de esta vocación provisional, el plus terminará asentándose durante el primer franquismo, desplazando al subsidio familiar como institución de protección familiar más relevante.

La controvertida naturaleza del plus de cargas familiares, su origen y fundamento sociopolítico, su especial lógica interna, su sistema de financiación de base empresarial y la extensa e intensa conflictividad que su aplicación e interpretación suscitó, hacen del plus familiar una de las instituciones históricas de seguridad social más peculiares. A analizar estos y otros extremos relativos al plus de cargas familiares se dedica el presente estudio.

\section{Fundamentos ideológicos de la protección de la familia en el primer franquismo}

El fin de la guerra civil trajo consigo la implantación de un nuevo modelo de Estado autoritario que, obviando los principios democráticos, apuesta decididamente por un intervencionismo normativo estatal en el ámbito de las organizaciones productivas y de las relaciones laborales. El Decreto de 13 de septiembre de 1936 por el que se declara fuera de la Ley a los partidos o agrupaciones políticas del Frente Popular, funcionarios y empleados de empresas públicas ${ }^{15}$, la Ley de 9 de febrero de 1939 de responsabilidades políticas ${ }^{16}$, y la Ley de 23 de septiembre de 1939 reorganizando la Dirección General de

1952 (BOE, 18 de octubre); cambio de denominación que mereció elogios por parte de la doctrina de la época, pues los hijos "lejos de ser una carga, son el primer bien del matrimonio". Cfr. FAGOAGA G. SOlANA, Miguel, "El plus familiar y el impuesto de utilidades", Cuadernos de Política Social, $\mathrm{n}^{\circ}$ 15, 1952 , p. 30. Junto al subsidio familiar y al plus familiar, durante el primer franquismo se mantuvieron y desarrollaron los subsidios a familias numerosas que se habían iniciado en la dictadura de Primo de Rivera. Vid. Ley de 1 de agosto de 1941, de protección a las familias numerosas, sustituida rápidamente por la Ley de 13 de diciembre de 1943 (BOE, 16 de diciembre de 1943). Sobre esta institución, cfr. Collantes dE Terán de la HerA, María José, "La política social en el nuevo Estado Franquista: protección a las familias numerosas", en ALEJANDRE GARCíA, Juan Antonio (coord.), Estudios jurídicos sobre el franquismo. La familia ideal y otras cuestiones, Madrid, Dykinson, 2009, p. 65-99.

14 CAPElla Martínez, Miguel y Esteban LóPEZ-ARAndA, Alfonso, Teoría y práctica del plus de cargas familiares, Madrid, Gráficas Sigma, 1946, p. 11.

15 Boletín Oficial de la Junta de Defensa Nacional de España, 16 de septiembre de 1936.

16 BOE, 13 de febrero de 1939. 
Seguridad ${ }^{17}$, evidencian "con claridad la naturaleza política que fundamentó la acción bélica” que llevó al poder al régimen franquista ${ }^{18}$.

El carácter totalitario del régimen instaurado tras la guerra civil queda reflejado en la extensión de lo político a todo tipo de relaciones sociales. Los primeros años del franquismo vienen marcados por un fuerte intervencionismo estatal, convirtiéndose el Estado en el actor más importante tanto en el ámbito público como en el privado y configurándose un modelo social basado en los principios inspiradores del nuevo régimen.

Como ha sido apuntado, la protección de la familia por el franquismo a través de la técnica de los seguros sociales está imbricada de una fuerte carga ideológica y propagandística. El Fuero del Trabajo, disposición que contenía los principios de política social que iban a regir las relaciones laborales durante el primer franquismo, ya anticipaba la importancia que el régimen había de conferir a la familia, considerándola como una de las materias de actuación normativa preferente de competencia estatal ${ }^{19}$. Partiendo de esta idea se pone a la familia al servicio de la ideología dominante ${ }^{20}$. El carácter programático del Fuero del Trabajo implicaba la necesidad de dictar normas que lo desarrollaran respetando sus principios, entre los que se encontraban los que siguen:

- El reconocimiento de la familia "como célula primaria natural y fundamento de la sociedad, y al mismo tiempo como institución moral dotada de derecho inalienable y superior a toda ley positiva" (declaración XII.3).

- La retribución del trabajo habrá de ser, "como mínimo, suficiente para proporcionar al trabajador y su familia una vida moral y digna" (declaración III.1 $)^{21}$.

\footnotetext{
${ }^{17}$ BOE, 26 de septiembre de 1939.

18 GonZÁlez-Posada MarTínez, Elías, El Derecho del Trabajo. Una Reflexión sobre su evolución histórica, Valladolid, Universidad de Valladolid, 1996, p. 96.

19 El Fuero del Trabajo fue considerado por la doctrina de la época como "una verdadera Carta social (...) una declaración de principios y auténtico programa (...) una auténtica parte dogmática constitucional". En este sentido, GARCía OvIEDO, Carlos, Tratado Elemental de Derecho Social, Sevilla, Librería General de Victoriano Suárez, 1946, p. 50-51. La trascendencia de esta norma vino reforzada por su declaración como Ley Fundamental de la Nación a través del artículo 10 de la Ley de Sucesión en la Jefatura de Estado, de 26 de julio de 1947 (BOE, 27 de julio).

20 MANRIQUe Arribas, Juan Carlos, "La familia como medio de inclusión de la mujer en la sociedad franquista", Hispania Nova. Revista de Historia Contemporánea, nº 7, 2007, p. 210 y ss.

${ }^{21}$ Cfr. exposición de motivos Orden 19 de junio de 1945 por la que se establece un plus de cargas familiares aplicable a las empresas dedicadas a la industria y al comercio que no lo tengan ya implantado
} 
- "Se establecerá el subsidio familiar por medio de organismos adecuados" (declaración III.2).

Con el fin de desarrollar estos y otros principios programáticos derivados del Fuero del Trabajo, y en cumplimiento del deber que tenía el Estado en relación con la protección de la familia, los primeros años del régimen franquista fueron una etapa de prolija producción normativa en esta materia. Toda la ordenación jurídica de la familia durante este periodo, incluida la normativa de previsión social, se funda en un concreto modelo de organización sociopolítico y económico, que se estructura ideológicamente en torno a los siguientes elementos 22 :

- La doctrina social de la Iglesia católica: el salario familiar. La vinculación del primer franquismo con la Iglesia católica y sus postulados resulta fuera de toda duda $^{23}$. La relación dialéctica entre el régimen totalitario y la ideología subyacente en el catolicismo más ortodoxo permea durante el franquismo en todos los ámbitos, afectando también a la previsión social familiar. La protección social de la familia en este periodo parte en buena medida de la doctrina social de la Iglesia católica y, en concreto, de su constructo teórico del salario familiar. De acuerdo con esta teoría, era preciso dotar al salario de un mayor sentido de justicia, para lo que era indispensable atender a las necesidades familiares del trabajador. En este sentido, se entiende que la retribución del trabajo no ha de atenerse exclusivamente a las reglas de oferta y demanda del mercado laboral, ni tampoco a la evaluación del rendimiento del trabajador o a la obra producida, sino que ha de contemplar la situación personal del trabajador en atención a sus cargas familiares ${ }^{24}$. Anticipada esta construcción en la encíclica de León XIII Rerum novarum (15 de mayo de 1891), es en el papado de Pio XI cuando, a través de Quadragesimo anno (15 de

en anteriores reglamentaciones, salvo excepciones que se indican (BOE, 30 de junio).

22 Todos los elementos que se señalan se articulan, esencialmente, en las doctrinas derivadas del catolicismo social, de indudable trascendencia en la política familiar franquista. Papel primordial en la fundamentación ideológica de las políticas familiares durante el primer franquismo desempeño Severino Aznar, auténtico artífice intelectual de las primeras acciones normativas dirigidas a proteger públicamente la familia. Vid. IGLESIAS DE USSEL, Julio, "La protección de la familia en España", Papeles de Economía Española, $\mathrm{n}^{\circ}$ 77, 1998, p. 227. El desarrollo de la doctrina de Aznar, ampliamente difundida en los primeros años del franquismo, en AZNAR, Severino, Del salario familiar al seguro familiar (evolución de una idea-fuerza), Santander, Ministerio de Organización y Acción Sindical, 1939, $3^{\text {a }}$ ed.

23 Vid., por todos, CASANOva RuIZ, Julián, La Iglesia de Franco, Barcelona, Crítica, 2005; y RUIZ RICO, Juan José, El papel político de la Iglesia Católica en la España de Franco, Madrid, Tecnos, 1977.

${ }^{24}$ Almansa Pastor, José Manuel, Derecho de la Seguridad Social, ob cit., p. 336. Sobre este punto, vid. Pallás-Vilaltella, Francisco, La doctrina social de la Iglesia sobre la condición y el trabajo de los obreros, Madrid, Espasa-Calpe, 1941, p. 233-242; y AZPIAZu, Joaquín, Orientaciones cristinas del Fuero del Trabajo, Burgos, Imprenta Aldecoa, 1939, p. 63-71. 
mayo de 1931), se consolida y desarrolla la teoría del salario familiar. En su apartado II.71, esta última encíclica condensa los elementos esenciales de la teoría católica del salario familiar, de acuerdo con la cual el salario del cabeza de familia (varón) debe ser suficiente para atender no solo las necesidades propias, sino también las familiares: "Ante todo, al trabajador hay que fijarle una remuneración que alcance a cubrir el sustento suyo y el de su familia. Es justo, desde luego, que el resto de la familia contribuya también al sostenimiento común de todos, como puede verse especialmente en las familias de campesinos, así como también en las de muchos artesanos y pequeños comerciantes; pero no es justo abusar de la edad infantil y de la debilidad de la mujer (...). Hay que luchar denodadamente, por tanto, para que los padres de familia reciban un sueldo lo suficientemente amplio para tender convenientemente a las necesidades domésticas ordinarias. Y si en las actuales circunstancias esto no siempre fuera posible, la justicia social postula que se introduzcan lo más rápidamente posible las reformas necesarias para que se fije a todo ciudadano adulto un salario de este tipo. No está fuera de lugar hacer aquí el elogio de todos aquellos que, con muy sabio y provechoso consejo, han experimentado y probado diversos procedimientos para que la remuneración del trabajo se ajuste a las cargas familiares, de modo que, aumentando éstas, aumente también aquél; e incluso, si fuere menester, que satisfaga a las necesidades extraordinarias".

Algunas realizaciones normativas del primer franquismo intentaron, más desde un plano teórico que práctico, profundizar en la técnica del salario familiar. Ilustrativas resultan a estos efectos las exposiciones de motivos de las ordenes que regularon el plus de cargas familiares en 1945 y 1946, que calificaban al plus familiar como el "primer paso hacia el salario familiar"25. Con todo, y más allá de proclamas y propuestas dogmáticas, lo cierto es que la teoría del salario familiar, relacionando la retribución del obrero con sus cargas familiares, resultaba una construcción insostenible jurídicamente atendiendo a los cimientos del derecho del trabajo; y ello, por cuanto el salario, en tanto prestación sinalagmática, se corresponde con otra prestación, el trabajo, en la que no influye de ningún modo el que el trabajador tenga más o menos cargas familiares ${ }^{26}$. Junto con esta inconsistencia ontológica, el modelo del salario familiar adolece de importantes lagunas en su lógica interna, desde el momento en que el sistema solo permite su aplicación a los trabajadores por cuenta ajena, desapareciendo la protección al cesar el trabajo, que es cuando mayor necesidad de ella se tiene. Por último, pero no menos importante, ha de

25 Orden 19 de junio de 1945; y Orden 29 de marzo de 1946 por la que se unifican las normas para la aplicación del Plus de Cargas Familiares, establecido por la Orden de 19 de junio de 1945 (BOE, 30 de marzo).

26 Alonso OlEA, Manuel, Instituciones de Seguridad Social, ob cit., p. 234. 
subrayarse que el salario familiar generaba efectos contrarios a los deseados en la práctica. Así, al ser soportadas las cargas familiares de modo indirecto por los empresarios, estos rehuían de los trabajadores con exceso de familia y optaban por trabajadores solteros. De este modo, la protección se volvía contra los protegidos, que ocultaban en ocasiones sus cargas familiares para evitar el desempleo ${ }^{27}$.

- El patrón de familia patriarcal y la consolidación de los roles y estereotipos de género. La protección de la familia en el franquismo promociona un concreto modelo familiar, la familia patriarcal, imponiendo unos estereotipos socioculturales muy rígidos. Se protegía un específico arquetipo de familia: el tradicional matrimonio con hijos en fase de formación, al que se adicionaba eventualmente algún pariente al que se consideraba dependiente. En el marco de este modelo, considerado como el único digno de protección, todo el desarrollo prestacional partía de una visión androcéntrica de la familia, persiguiendo la perpetuación de los roles más arcaicos y conservadores. Así, las políticas previsionales se dirigían a los riesgos familiares, entendidos como el defecto de rentas o el exceso de gastos que el obrero varón tenía que soportar como consecuencia de la construcción familiar tradicional. Se opta, en consecuencia, por impulsar una política familiar tradicionalista y conservadora de corte autoritario que, "con el auxilio de la Iglesia, pondrá a la familia al servicio de los intereses del nuevo Estado. Y al individuo al servicio de la institución familiar"28; y ello, por cuanto es "consigna rigurosa de nuestra Revolución elevar y fortalecer la familia en su tradición cristiana, sociedad natural perfecta y cimiento de la Nación"29.

Especial atención merece en este constructo el rol de la mujer, que aparece como eje vertebrador de la organización familiar, reservándole el papel reproductivo y asignándole los roles de esposa, madre y cuidadora; roles que se asocian a valores estereotipados como el sacrificio, la obediencia y la subordinación al varón. Ya en la declaración II.1 del Fuero del Trabajo se imponía al Estado la obligación de libertar "a la mujer casada del taller y de la fábrica". En cumplimiento de este principio programático, la instauración del plus de cargas familiares tiene como fin primordial "reintegrar al hogar a las mujeres casadas que trabajan por cuenta ajena" 30 .

\footnotetext{
27 Almansa Pastor, José Manuel, Derecho de la Seguridad Social, ob cit., p. 337.

28 IgLESIAS DE USSEL, Julio y FlAQUER, Lluis, "Familia y análisis sociológico: el caso de España", Revista Española de Investigaciones Sociológicas, n 61, 1993, p. 61.

${ }^{29}$ Exposición de motivos Ley de Bases de 18 de julio de 1938, por la que se crea el régimen obligatorio de subsidios familiares (BOE, 19 de julio de 1938).

${ }^{30}$ Exposiciones de motivos Orden 19 de junio de 1945 y Orden 29 de marzo de 1946.
} 
La función de la mujer en la institución familiar venía fundamentada en la propia doctrina social de la Iglesia católica, que entendía que las "madres de familia trabajarán principalísimamente en casa o en sus inmediaciones, sin desatender los quehaceres domésticos. Constituye un horrendo abuso, y debe ser eliminado con todo empeño, que las madres de familia, a causa de la cortedad del sueldo del padre, se vean en la precisión de buscar un trabajo remunerado fuera del hogar, teniendo que abandonar sus peculiares deberes y, sobre todo, la educación de los hijos" 31 . Así, la mujer asume el rol en la familia franquista de madre, esposa y organizadora del hogar ${ }^{32}$. Externamente, en el plano social, las posibilidades de intervenir son muy escasas, aspecto que se traduce en la desaparición del "modelo de mujer trabajadora, profesional, independiente en el terreno económico" 33 .

- Fomento e incentivación de la natalidad. El problema de decrecimiento de la natalidad debido a la escasez y a la carestía de vida constituía una de las mayores preocupaciones de los políticos y sociólogos de la época. De acuerdo con la concepción moral imperante en el régimen totalitario, la patria exigía una "prole numerosa"34. La situación de España a este respecto era preocupante, pues tras la guerra civil, en nuestro país "los coeficientes de natalidad disminuyen y la dinámica de la población es muy exigua", y únicamente "los pueblos de familias fecundas pueden extender la raza por el mundo y crear y sostener imperios. La vitalidad demográfica acrecienta la personalidad internacional y la potencia militar. Preocupación principal del Nuevo Estado nacional-sindicalista debe ser, pues, la política demográfica" ${ }^{35}$. Sin perjuicio de su indudable trascendencia, la promoción de la natalidad ha de tener como límite el punto en que "se rompa el equilibrio económico de su hogar y llegue la miseria, obligando a la madre a buscar en la fábrica o taller un salario con que cubra la insuficiencia del conseguido por el padre, apartándola de su función suprema e insustituible que es la de preparar sus hijos, arma y base de la Nación, en su doble aspecto espiritual y

\footnotetext{
${ }^{31}$ Quadragesimo anno (apartado II.71).

32 Cfr. Roca I Girona, Jordi, "Esposa y madre a la vez. Construcción y negociación del modelo ideal de mujer bajo el (primer) franquismo", en NIELFA CRISTÓBAL, Gloria (ed.), Mujeres y hombres en la España franquista: sociedad, economía, política y cultura, Madrid, Editorial Complutense, 2003, p. 45 y ss.

33 FRAnco RUBIO, Gloria, "De la vida doméstica a la presencia pública: las mujeres en las cortes franquistas", en PÉREZ CANTó, Pilar (ed.), De la democracia ateniense a la democracia paritaria, Barcelona, Icaria Editorial, 2009, p. 188. Sobre el tratamiento jurídico-laboral de la mujer durante el franquismo, vid. ESPUNY TOMÁs, María Jesús, "Aproximación histórica al principio de igualdad de sexos (IV): De la Ley de Contrato de Trabajo de 1944 a las últimas disposiciones franquistas", IUSLabor, no 1 , 2008.

${ }^{34}$ Exposición de motivos Ley de Bases de 18 de julio de 1938, por la que se crea el régimen obligatorio de subsidios familiares.

35 Preámbulo Ley 1 de agosto de 1941, de protección a las familias numerosas.
} 
material"36. De este modo, en ningún caso la natalidad puede implicar que la madre abandone su rol de cuidadora y madre para insertarse en el mundo laboral, pues ello supondría la "corrupción del carácter propio de la mujer y de su dignidad de madre; es trastorno de toda la sociedad familiar, con lo cual al marido se le priva de la esposa, a los hijos de la madre y a todo el hogar doméstico del custodio que lo vigila siempre" 37 .

- Defensa y estímulo del matrimonio católico como condición legal para la constitución familiar y para la natalidad. El régimen franquista, acogiendo la doctrina eclesiástica más ortodoxa, considera que se hace precisa una política familiar basada en el matrimonio católico, con el fin de evitar el "relajamiento de los sentimientos morales, y la debilitación de las creencias religiosas" 38 . Se sigue en este punto la doctrina de la Iglesia católica plasmada por Pio XI en la encíclica Casti Connubii (31 de diciembre de 1930), que recoge la doctrina de Leon XIII en la encíclica Arcanum Divinae Sapientiae (10 de febrero de 1880). De este modo, solo el matrimonio católico puede tener relevancia jurídica, porque solo a través de dicha institución la sociedad conyugal cumple su finalidad plenamente, que "no sólo (es) la propagación del género humano, sino también la de engendrar la prole de la Iglesia, conciudadanos de los santos y domésticos de Dios"39.

- Visión comunitaria de la empresa. La protección a la familia desde las políticas públicas de previsión social durante las primeras décadas del franquismo obedece a la visión unitaria que tiene el régimen autoritario de las relaciones laborales, de acuerdo con la cual no existen intereses contrapuestos entre empresarios y trabajadores, sino un único fin común, una única comunidad de vida, lo que implica la negación del conflicto entre las partes de la relación laboral ${ }^{40}$. Esta visión comunitaria de la empresa se instaura normativamente en la Ley de Contrato de Trabajo de $1944^{41}$, que proclama el origen armónico y contractual de la relación de trabajo basado en una identidad de intereses y en la comunidad de propósitos de empresario y trabajadores. La concepción comunitaria de la empresa tiene

\footnotetext{
${ }^{36}$ Exposición de Motivos Ley de Bases de 18 de julio de 1938, por la que se crea el régimen obligatorio de subsidios familiares.

${ }^{37}$ Casti Connubi (apartado 27).

38 García OvIEDo, Carlos, Tratado Elemental de Derecho Social, Madrid, EISA, 1954, 6ª ed., p. 831.

${ }^{39}$ Arcanum Divinae Sapientiae (apartado 8).

40 Ramírez Martínez, Juan Manuel (Director), Curso de Derecho del Trabajo, Valencia, Tirant lo Blanch, 2003, 12 ed., p. 33.

${ }^{41}$ Decreto de 26 de enero de 1944 por el que se aprueba el texto refundido del Libro I de la Ley de Contrato de Trabajo (BOE, 24 de febrero).
} 
"aspectos armonicistas directos", constituyendo el plus de cargas familiares una de sus manifestaciones más patentes ${ }^{42}$.

- El interés nacional como valor supremo al que deben subordinarse el resto de valores económicos, sociales e incluso humanos. El interés nacional es el sustento último de la normativa de previsión social familiar, debiendo el Estado regular esta materia con el fin de salvaguardar la fuerza del trabajo que haga posible la reconstrucción de un Estado destruido tras la contienda civil. La mejora de las condiciones de la familia obrera resulta trascendente en la medida que ayuda al interés nacional, y es esta finalidad la que en última instancia anima al legislador a su intervención normativa. Con este mismo fundamento se configura de modo subsidiario el deber del empresario de proteger a la familia obrera, como una mera extensión del deber del Estado de proteger el interés nacional y la paz social.

Todas las anteriores consideraciones llevan al Estado a reconocer y amparar a la "familia como institución natural y fundamento de la sociedad, con derechos y deberes anteriores y superiores a toda Ley humana positiva. El matrimonio será uno e indisoluble. El Estado protegerá especialmente a las familias numerosas" (artículo 22 Fuero de los Españoles) ${ }^{43}$.

\section{La institucionalización de la protección familiar en el primer franquismo: alcance y dinámica del plus familiar}

La declaración III.2 del Fuero del Trabajo recoge como uno de los principios programáticos del nuevo régimen el establecimiento de subsidios familiares a través de organismos adecuados. La ubicación de este reconocimiento lejos de la declaración de previsión y seguros sociales (declaración X), y la no inclusión del subsidio familiar entre los seguros sociales que dicha declaración contenía (declaración X.2), parecía apuntar a que la protección familiar no se sometería al modelo de seguros sociales, sino que se conformaría con carácter asistencial ${ }^{44}$. Sin embargo, la Ley de Bases de 18 de

\footnotetext{
42 PurCalla Bonilla, Miguel Ángel y JORDÀ FeRnÁNDEZ, Antoni, Las relaciones laborales en España hasta la Constitución de 1978, Madrid, Dykinson, 2007, p. 100.

43 BOE, 18 de julio de 1945. En análogo sentido, los principios V y VI de la Ley Fundamental de 17 de mayo de 1958, por la que se promulgan los principios del movimiento nacional (BOE, 19 de mayo) se refieren a que la comunidad nacional se funda en el hombre y "en la familia, como base de la vida social", y a que las "entidades naturales de la vida social, familia, municipio y sindicato, son estructuras básicas de la comunidad nacional”, respectivamente.

44 Almansa PAStor, José Manuel, Derecho de la Seguridad Social, ob cit., p. 340. Dispone literalmente la declaración X.2 del Fuero del Trabajo que: "Se incrementarán los seguros sociales de: vejez, invalidez, maternidad, accidentes del trabajo, enfermedades profesionales, tuberculosis y paro forzoso, tendiéndose a la implantación de un seguro total. De modo primordial se atenderá a dotar a los trabajadores
} 
julio de 1938 disipa las dudas rápidamente e instaura el régimen de subsidios familiares a modo de seguro social general. Pocos años más tarde, el subsidio familiar se vería complementado con el plus de cargas familiares. Ambas instituciones comparten su fundamento y finalidad, calificándose sus diferencias como "accidentales, de oportunidad técnica o práctica"45.

Subsidio familiar y plus de cargas familiares son las instituciones esenciales que el franquismo implementará para proteger a la familia desde la perspectiva de la seguridad social. Pese a que ambas tienen un restringido campo de aplicación, excluyendo de su ámbito a los trabajadores por cuenta propia, pensionistas o personas sin empleo, y otorgando protección sobre una base profesional, su importancia radica en que ambas cristalizan el tránsito de la técnica del salario familiar y de la protección de la familia diluida en otros seguros sociales a la creación de seguros sociales específicos familiares ${ }^{46}$.

\subsection{Antecedentes, origen y desarrollo del plus familiar}

El plus de cargas familiares surge en gran medida para complementar la ineficacia del subsidio familiar en el cumplimiento de su finalidad: satisfacer las necesidades más perentorias de los obreros. El subsidio familiar es implantado pocos años antes que el plus familiar, mediante la Ley de Bases de 18 de julio de 1938, y se desarrolla reglamentariamente por el Decreto de 20 de octubre de $1938^{47}$. Se puede considerar como una de las primeras medidas de previsión social en materia de prestaciones familiares en sentido estricto, dirigida directamente a sufragar la tenencia de familiares a cargo ${ }^{48}$. Pese a su denominación, constituye un auténtico seguro, pues concurren en él las características de un seguro social: aportación tripartita (Estado, patronos y asegurados), riesgo asegurable (carga familiar), gestión por la Administración y obligatoriedad del régimen (Caja Nacional de Subsidios Familiares, integrada en el

ancianos de un retiro suficiente".

${ }^{45}$ Fagoaga G.- Solana, Miguel, "El plus familiar y el impuesto de utilidades", ob cit., p. 31.

46 Buenaga Ceballos, Óscar, La familia y la Seguridad Social, ob cit., p. 115 y 116. La doctrina de la época criticó la dualidad de mecanismos de previsión familiar, abogando por la unificación del subsidio y del plus familiar en un único seguro social. Vid. FagoAga G.-Solana, Miguel, "El plus familiar y el impuesto de utilidades", ob cit., p. 31.

${ }^{47}$ BOE, 26 de octubre de 1938.

48 Buenaga Ceballos, Óscar, La familia y la Seguridad Social, ob cit., p. 115. Algún sector doctrinal, yendo más allá, lo considera como la primera manifestación de la introducción en nuestro sistema de seguridad social de la protección a la familia. Montoya Melgar, Alfredo, "El Instituto Nacional de Previsión, fundamento de la protección social española”, en TORTUERo PLAZA, José Luis (Director), Cien años de Protección Social en España, ob cit., p. 174 y 175. 
Instituto Nacional de Previsión) ${ }^{49}$. De este modo, el subsidio familiar encarna un auténtico seguro social familiar que, aunque limitado en su aplicación a los trabajadores por cuenta ajena, desvincula la prestación familiar del salario ${ }^{50}$. Consiste en una prestación que se abona al asegurado cabeza de familia que tenga dos o más hijos menores de catorce años o incapacitados para el trabajo a su cargo, y se materializa en un importe igual para todos los trabajadores- con independencia de sus condiciones salariales- de acuerdo con una escala. Su desarrollo reglamentario extendió la protección del subsidio a nietos y hermanos del trabajador que no tengan por otro motivo derecho al subsidio y cuyos padres hayan muerto o estén incapacitados para el trabajo ${ }^{51}$. Dentro del régimen de subsidios familiares se insertan unas prestaciones complementarias (subsidios de escolaridad ${ }^{52}$, de orfandad y de viudedad) ${ }^{53}$ y unos premios (nupcialidad y natalidad) ${ }^{54}$.

La disminución del poder adquisitivo de los salarios en los primeros años del franquismo y la escasez de las prestaciones derivadas del subsidio familiar, llevaron al régimen a buscar "nuevos instrumentos en los que plasmar el discurso de fortalecimiento de la familia como la célula social y política en la que se apoyaba la nación" "55. Con esa finalidad, y complementando el exiguo subsidio familiar, surge el plus de cargas familiares. En un primer momento, el plus se inserta en el modelo de relaciones laborales franquista a través de las reglamentaciones nacionales de trabajo ${ }^{56}$; instrumentos normativos que, teniendo en cuenta la prohibición de negociar convenios colectivos impuesta por el régimen franquista, asumen la tarea de poder mejorar las

49 García Oviedo, Carlos, Tratado Elemental de Derecho Social (6 ${ }^{\mathrm{a}}$ ed.), ob cit., p. 854.

50 Base $3^{\text {a }}$ Ley de Bases de 18 de julio de 1938, por la que se crea el régimen obligatorio de subsidios familiares.

51 Artículo 11 Decreto 20 de octubre de 1938.

52 Orden de 7 de diciembre de 1939 (BOE, 13 de diciembre).

53 Inicialmente, la Ley de 18 de julio de 1938 limitó el derecho al subsidio a los trabajadores activos, extendiéndose los beneficios de la misma a las viudas y huérfanos de los trabajadores fallecidos, siempre que concurran determinadas circunstancias, a través de la Ley de 23 de septiembre de 1939 (BOE, 8 de octubre). Mediante esta última de disposición se incluye dentro del sistema protector del subsidio familiar "el momento más difícil de la vida económica familiar: el del fallecimiento del padre, cuando, por no ser la mujer trabajadora activa, carece del carácter de subsidiada" (exposición de motivos Ley 23 de septiembre de 1939).

${ }^{54}$ Vid. Decreto de 22 de febrero de 1941 (BOE, 7 de marzo), Decreto de 29 de diciembre de 1948 (BOE, 18 de enero de 1949) y Orden de 5 de mayo de 1949 (BOE, 7 de mayo).

55 Molinero, Carme, "Falange y la construcción del régimen, 1939-1945. La búsqueda de unas bases sociales”, en RUIZ CARNICER, Miguel Ángel (coord.), Falange, las culturas políticas del fascismo en la España de Franco (1936-1975) (vol. I), Zaragoza, Institución Fernando el Católico, 2013, p.192.

${ }^{56}$ Ley de 16 de octubre de 1942 por la que se establecen normas para regular la elaboración de las reglamentaciones de trabajo (BOE, 23 de octubre). 
prestaciones de seguridad social en materia de riesgos comunes ${ }^{57}$. El primer instrumento que lo recoge es la Reglamentación nacional de trabajo de la banca privada, aprobada por Orden de 28 de abril de 1942, reproduciéndose en múltiples reglamentaciones posteriores $^{58}$.

La proliferación del plus familiar en las reglamentaciones supuso que, en apenas tres años, la ordenación del plus abandonara el escenario sectorial diseñado por estos instrumentos normativos, trasladándose su regulación a normas con vocación de generalidad. Así, y con el fin de unificar la configuración de este plus, extendiéndolo además a sectores productivos que aún no lo contemplaban, se dicta la Orden de 19 de junio de 1945, que amplía el ámbito del plus de cargas familiares a aquellas empresas cuyos trabajadores no lo disfrutaran, sin perjuicio de lo que dispusieran las reglamentaciones que acordasen un porcentaje superior al establecido por la orden. Esta disposición es sustituida por la Orden de 29 de marzo de 1946, que deroga todas las normas relativas a pluses de cargas familiares hasta entonces vigentes y los regímenes especiales de aplicación del plus en determinadas actividades y empresas, unificando el régimen del plus de cargas familiares 59 . La norma recoge "en una sola disposición unificadora las mejoras, modificaciones y aclaraciones a que ha dado lugar la aplicación del sistema, sometiendo a estas normas generales todas las actividades no excluidas de modo expreso y terminando con la multiplicidad de preceptos sobre el Plus que, al resolver con criterio dispar casos similares, sembraban algunas veces dudas y confusiones, manteniendo tan solo las diferencias en el porcentaje destinado a Plus que las Reglamentaciones o Normas específicas de diversas actividades establecen"60. Con posterioridad, y a través de la Orden de 16 de octubre de 1952, el plus de cargas familiares varía su denominación a plus familiar.

La compleja naturaleza del plus de cargas familiares y las numerosas lagunas e imprecisiones en su ordenación jurídica, generaron múltiples dudas interpretativas y aplicativas que fueron resueltas por una ingente jurisprudencia administrativa ${ }^{61}$. Junto

\footnotetext{
${ }^{57}$ MARTínEZ GiRÓN, Jesús, "La etapa de previsión social en España”, ob cit., p. 437.

58 Entre otras reglamentaciones, implantaron el plus familiar las siguientes: minas de carbón (6 de junio de 1942), minas de plomo (16 de julio de 1942), Tranvías de Madrid (25 de julio de 1942), industria metalgráfica (1 de octubre de 1942), Metropolitano de Madrid (10 de febrero de 1943), industria resinera (16 de marzo de 1943), industria textil-lana (28 de marzo de 1943), industria textil-algodón (1 de abril de 1943), Tranvías de Valencia (16 de junio de 1943), compañías de seguros (30 de junio de 1943), industria físico-farmacéuticas (6 de agosto de 1943), artes gráficas (23 de febrero de 1944), industria hotelera, cafés, bares y similares (30 de mayo de 1944), cinematografía (28 de septiembre de 1944), prensa (22 de diciembre de 1944), y siderometalúrgica (28 de julio de 1945).

${ }^{59}$ Artículos 5 y 32 Orden 29 de marzo de 1946.

${ }^{60}$ Exposición de motivos Orden de 29 de marzo de 1946.

${ }^{61}$ Alonso OlEa, Manuel, "La Ley de 15 de julio de 1954, por la que se establece la ayuda familiar para
} 
con las abundantes resoluciones de la Dirección General de Trabajo (DGT), tampoco faltaron resoluciones judiciales orientadas a la delimitación de algunos puntos conflictivos del plus familiar. Entre todos los elementos controvertidos, su ámbito de aplicación, los beneficiarios y el mecanismo de reparto del plus fueron los más destacados. En el análisis de estos aspectos, como se verá posteriormente, el papel de la denominada jurisprudencia administrativa adquiere una vital importancia, asumiendo en ocasiones la DGT una auténtica función normativa.

\subsection{Financiación y administración del plus familiar}

Con su reconocimiento normativo, el plus de cargas familiares se inserta de lleno en el incipiente e imperfecto sistema de previsión social que se iba conformando durante el primer franquismo, complementado al subsidio familiar en su vocación protectora de la institución familiar. Pese a que el plus de cargas familiares obedecía a la misma finalidad tutelar de la familia obrera que tenía el subsidio familiar, su peculiar y específica configuración jurídica le dotaba de unas especiales características que le diferenciaban claramente de esta última institución. Entre otras, cabe subrayar dos esenciales: su régimen de financiación y su modelo de gestión y administración.

Respecto a la financiación del plus, esta corre a cargo exclusivo de la empresa. El plus familiar se satisface a los trabajadores con cargo a un fondo empresarial constituido en cada organización productiva y que está compuesto por un tanto por ciento de la nómina o por el porcentaje que se fije para cada actividad. El porcentaje original establecido en el artículo 6 Orden 29 de marzo de 1946 fue, como regla general, del 10\%; porcentaje que se fue ampliando por distintas normas reglamentarias y sectoriales, oscilando entre un $15 \%$ y un $35 \%$ del salario total ${ }^{62}$. A los efectos de calcular el plus de cargas familiares, el porcentaje que corresponda se aplicará sobre la nómina real (totalidad de las cantidades abonadas el trimestre natural anterior al personal de la empresa incluido en el sistema previsional del plus de cargas familiares). Dentro de la nómina real han de entenderse incluidas las comisiones, primas a la producción, horas extraordinarias, retribución dominical, subvenciones por carestía de vida y gratificaciones. Por el contrario, no se considerarán integrando la nómina a estos efectos las dietas, viáticos o

funcionarios públicos civiles", Revista de Administración Pública, nº 14 (1954), p. 220.

62 El porcentaje según actividad se puede consultar en SALAS MonTILla, Cristóbal, Distribución de los puntos en el plus familiar, Barcelona, Casa Provincial de Caridad, 1955, 5 a ed., p. 19-23; y en FERNÁNDEZ HERAS, Amado, Normas únicas para aplicación del plus familiar, Zaragoza, La Editorial Lasala y Cía., 1956, 12 ed., p. 38-41. La doctrina entendió como un porcentaje promedio acertado el 25\% del salario. Vid. Hernainz Márquez, Miguel, Tratado Elemental de Derecho del Trabajo, Madrid, Instituto de Estudios Políticos, 1961, 8 a ed., p. 376. Otros autores rebajan este porcentaje al 20\%. Vid. Alonso OleA, Manuel, Instituciones de Seguridad Social, ob cit., p. 239. 
indemnizaciones similares ${ }^{63}$. El Decreto de 21 de marzo de 1958, sobre retribuciones voluntarias de las empresas a sus trabajadores ${ }^{64}$, dispuso que determinadas retribuciones voluntariamente concedidas por las empresas y las primas de producción, incentivos y remuneraciones por rendimiento no se tuvieran en cuenta a efectos del plus familiar.

Por lo que se refiere a la administración y gestión del plus, estas tareas se desarrollaban íntegramente en el ámbito empresarial, si bien contaban con supervisión y control público. La administración y gestión del plus de cargas familiares corresponde a la empresa. Las dudas que su aplicación pueda generar deberán resolverse por una comisión que habrá de constituirse en cada centro de trabajo. Esta comisión está integrada por el jefe del centro de trabajo (o persona en quien delegue); por el enlace sindical, que será el designado por el sindicato correspondiente cuando haya varios; y, por un número de vocales electivos (centros con menos de 51 trabajadores, dos vocales; centros entre 51 y 250 trabajadores, tres vocales; centros con más de 250 trabajadores, 4 vocales). Los vocales serán escogidos por los trabajadores del centro laboral con arreglo a las mismas normas de las elecciones sindicales, debiendo haber tantos suplentes como vocales existan en el centro de trabajo. La aceptación del cargo de vocal es obligatoria, debido a la función social que desempeñan, y solo se podrá renunciar por justa causa ${ }^{65}$. El número de trabajadores integrantes de la comisión podrá ser ampliado previa decisión del Delegado de Trabajo, quien los designará directamente. También la Delegación de Trabajo podrá remover a aquellos vocales que desatiendan sus obligaciones, pero deberán hacerlo previa instrucción del oportuno expediente en el que siempre será oída la organización sindical. Estas dos competencias del poder político en relación con los vocales obreros evidenciaban el escaso papel que, en la práctica, desempeñaban los trabajadores en el seno del organismo gestor del plus.

La comisión del plus familiar conocerá en un primer término de las reclamaciones que se formulen en relación con el plus en el centro de trabajo. Contra los acuerdos de la comisión se podrá interponer recurso ante la central de la empresa y, frente a los fallos de esta, recurso ante la Delegación de Trabajo en diez días laborables desde la notificación. Frente a las resoluciones de este organismo podrá interponerse recurso ante la DGT en idéntico plazo66. Las funciones que teóricamente se atribuían a las

63 Artículo 7 Orden 29 de marzo de 1946. Existieron excepciones de los conceptos que deben computar a efectos del plus en determinados sectores de actividad como hostelería, peluquerías o marina mercante. Cfr. Salas Montilla, Cristóbal, Distribución de los puntos en el plus familiar, ob cit., p. 26 y 27.

${ }^{64}$ BOE, 1 de abril de 1958.

65 Salas Montilla, Cristóbal, Distribución de los puntos en el plus familiar, ob cit., p. 29.

${ }^{66}$ Artículo 28 Orden de 29 de marzo de 1946, en su redacción por Orden de 24 de enero de 1956 (BOE, 31 de enero). Esta última norma preveía la eliminación de estas comisiones, cuyas funciones serían asignadas a los jurados de empresa en cuanto estos fueran constituidos. La creación de los jurados de empresa supuso la materialización del concepto franquista de la empresa como una comunidad de vida, 
comisiones del plus familiar eran amplísimas, aunque en la práctica se convirtieron en meros centros de cálculo ${ }^{67}$.

Las peculiaridades señaladas en relación con la financiación y la administración del plus tienen dos consecuencias directas. La primera, que el plus de cargas familiares tuviera prestaciones más sustanciosas que el subsidio familiar. En este sentido, al recaer la organización y gestión del plus plenamente en el ámbito interno de la empresa, con menores gastos de administración, los trabajadores salían, a limine, beneficiados en el importe de sus prestaciones familiares ${ }^{68}$. La segunda, que el montante del plus familiar difiriera en cada empresa. El hecho de que el plus de cargas familiares dependiera de fondos constituidos a nivel de la propia empresa con un porcentaje de las nóminas de sus obreros, implicaba que el importe fuera variable en función de cada empresa, y que su alcance dependiera del número de obreros de la organización, de sus retribuciones y de los familiares a cargo que tuvieran los diferentes miembros de la plantilla. Además, y pese a que la regulación era única (Orden de 29 de marzo de 1946), el porcentaje de la nómina constitutivo del plus se podía regular por las reglamentaciones de trabajo o normas laborales de general aplicación en alguna actividad ${ }^{69}$. La variabilidad en la cuantía del plus mereció duras críticas por parte de la doctrina, pues suponía tratar desigualmente una misma situación de necesidad ${ }^{70}$. La contradicción era evidente, pues

siendo su finalidad principal, tal y como dispone el artículo 1 Decreto de 18 de agosto de 1947 por el que se crean los jurados de empresa (BOE, 9 de octubre): "hacer efectiva en el seno de la misma la colaboración entre el capital, la técnica y la mano de obra en sus distintas modalidades, al servicio de la mayor concordia entre los distintos elementos que constituyen la producción, del incremento racional de la misma y del mayor rendimiento en el trabajo". La propia exposición de motivos de la norma fundacional conceptúa los jurados de empresa como "un instrumento idóneo de colaboración constructiva", pero sin menoscabo de "las facultades de dirección que incumbe a los jefes de empresa". En palabras de la doctrina de la época, se pretendía que a través de los jurados de empresa "el empresario, el técnico y el obrero, fundidos en una tarea común, con idénticos fines a lograr y teniendo que discurrir por idénticos cauces" constituyeran "una perfecta e indisoluble unidad". En este sentido, VILLAR PALASÍ, José Luis y MuÑOZ CAMPOS, Juan, Jurados de Empresa, Madrid, SIPS DNS, 1950, p. 205. Sin embargo, y pese a que los jurados de empresa querían presentarse como representantes mixtos o unitarios del conjunto de elementos que componían la empresa como comunidad de vida, los mismos resultaban ser un mero intento "más o menos utópico, de superar con un artificio legal la contraposición de intereses característica de las relaciones contractuales". Vid. MONTOYA MELGAR, Alfredo, La representación sindical en la empresa, Sevilla, Instituto García Oviedo- Universidad de Sevilla, 1968, p. 43.

67 Salas Montilla, Cristóbal, Distribución de los puntos en el plus familiar, ob cit., p. 31. Vid. Resolución DGT 7 de junio de 1954.

68 Hernainz Márquez, Miguel, Tratado Elemental de Derecho del Trabajo, ob cit., p. 372. Cfr. FERNÁNDEZ HERAS, Amado, Aplicación general del plus de cargas familiares en la industria y el comercio, Zaragoza, Tip. La Editorial, 1945, p. 1.

69 Artículo 5 Orden de 29 de marzo de 1946.

70 Alonso García, Manuel, Política social española en relación con la familia, Madrid, Ediciones del Congreso de la Familia Española, 1958, p. 36. 
dos trabajadores con igual categoría, en el mismo sector de actividad y con idénticas cargas, podían tener pluses con importes muy dispares. Sin embargo, y como posteriormente se desarrollará, de esta situación no cabe colegir que el plus pueda ser considerado como una clase de salario, teniendo en cuenta que no existe posibilidad jurídica de insertar el plus de cargas familiares "en la estructura del contrato de trabajo para relacionar la contraprestación por el trabajo con las cargas familiares de quien lo ejecuta"71.

\section{3. Ámbito de aplicación}

Como se ha expuesto, el plus de cargas familiares era satisfecho por las empresas a sus trabajadores en atención a las cargas que estos tuvieran. De acuerdo con el artículo 1 Orden 29 de marzo de 1946, el plus se aplica a todos los trabajadores por cuenta ajena, cualquiera que sea su actividad laboral y el carácter de la empresa o entidad privada o pública de que dependan, siempre que no se encuentren expresamente excluidos por la regulación de la institución. Pese a su aparente universalidad, el plus de cargas familiares contaba con las mismas limitaciones y exclusiones que habían venido acompañando al incipiente modelo de los seguros sociales. Por una parte, se excluía cualquier tipo de cobertura para el trabajo por cuenta propia; y, por otra, no se incluía al sector primario. Junto con estas excepciones, el plus no resultaba tampoco aplicable al trabajo a domicilio (salvo normativa específica en contra) ni al trabajo doméstico, perpetuando la exclusión de ambas modalidades de trabajo, altamente feminizados, y que resulta ya una constante en la evolución histórica de nuestra normativa jurídicolaboral.

En primer lugar, quedan excluidos de la percepción del plus familiar al no estar sus actividades incluidas en la Ley de Contrato de Trabajo ${ }^{72}$ :

- Los trabajos de carácter familiar donde solamente estén ocupadas personas de la familia o por ella aceptadas, bajo la dirección de uno de sus miembros, siempre que los que trabajen no se consideren asalariados.

- Los trabajos que, sin tener carácter familiar, se ejecuten ocasionalmente mediante

\footnotetext{
71 AlONSO OLEA, Manuel, Instituciones de Seguridad Social, ob cit., p. 238.

72 Artículo 2 Orden 29 de marzo de 1946 y artículo 2 Decreto de 26 de enero de 1944 por el que se aprueba el texto refundido del Libro I de la Ley de Contrato de Trabajo. En la aplicación de estas exclusiones se generaron los clásicos problemas derivados de las denominadas zonas grises del derecho del trabajo. Así, se cuestionó la aplicación del plus a los agentes comerciales (STS 28 de noviembre de 1952); a los comisionistas (STS 29 de octubre de 1954); a los contratistas (STS 12 de noviembre de 1954); a los representantes (STS 21 de diciembre de 1953); y a los transportistas (STS 23 de abril de 1954), entre otros colectivos.
} 
los llamados servicios amistosos, benévolos y de buena vecindad.

- El servicio doméstico, entendiéndose por tal el que se preste mediante jornal, sueldo, salario o remuneración de otro género o sin ella, y que sea contratado; no por un patrono, sino por un amo de casa que no persiga fin de lucro para trabajar en una casa o morada particular al servicio exclusivo del contratante, de su familia o de sus dependientes, bien se albergue en el domicilio del amo o fuera de él.

En segundo lugar, tampoco resultará de aplicación el plus de cargas familiares a los siguientes colectivos ${ }^{73}$ :

- Trabajadores que desempeñen en los centros de trabajo las funciones de alta dirección, alto gobierno o alto consejo (p. ej. director general, director o gerente de la entidad, subdirector, inspector general, secretario general) y que resulten excluidos en las correspondientes reglamentaciones de trabajo. Esta exclusión generó mucha conflictividad en lo que atañe a los apoderados de las compañías, entendiéndose que el mero apoderamiento no implicaba por sí mismo la retirada del plus familiar, sino que era necesario que el poder fuera amplio para excluir su percepción ${ }^{74}$.

- Trabajadores agrícolas, forestales y pecuarios.

- Trabajadores a domicilio, salvo en los casos de que concretamente se disponga otra $\operatorname{cosa}^{75}$.

- Trabajadores de actividades en las cuales la mayoría del personal trabaje a la parte como modo exclusivo de remuneración.

- Alto personal artístico.

- Personal que se encuentre taxativamente excluido de la aplicación de la reglamentación correspondiente.

\footnotetext{
73 Artículos 3 y 4 Orden 29 de marzo de 1946.

74 Cfr. Resolución DGT 27 de mayo de 1946 y STS 18 de enero de 1954.

75 En la práctica, la mayoría de reglamentaciones que empleaban habitualmente trabajadores a domicilio les reconocieron el derecho a percibir el plus familiar, si bien con determinadas particularidades. Entre otras, las de las siguientes actividades: calzado, punto, guantes de piel, alpargateras, esparto, industrias fotográficas, confección, vestido y tocado, repujado, marroquinería y similares, industria manual del cáñamo, y fabricación manual de hilados y redes para la pesca de arrastre y confección de prendas de peletería. Vid. FERnÁndez HeRAS, Amado, Normas únicas para aplicación del plus familiar, ob cit., p. 56 y ss.
} 


\subsection{Beneficiarios}

Tendrá derecho a percibir el plus familiar el trabajador por cuenta ajena en activo por determinados familiares que convivan con él y que vivan a su cargo y expensas. No obstante, este principio tiene numerosas excepciones y particularismos. Así, en ocasiones el plus será cobrado por trabajadores que no están en activo (servicio militar en algunas actividades, enfermos y accidentados, despedidos injustamente por los salarios dejados de percibir, trabajadores en vacaciones o permisos) ${ }^{76}$. También se puede ser acreedor del plus por familiares con los que no se conviva en determinadas circunstancias (hijos internos en colegios, seminarios, sanatorios o manicomios, cuando el trabajador sufrague sus gastos, por ejemplo) ${ }^{77}$.

Sin menoscabo de las excepciones expuestas, y con carácter general, tendrán derecho a la percepción del plus de cargas familiares:

- Los trabajadores casados.

- Los trabajadores casados con hijos.

- Los trabajadores viudos con o sin hijos.

- Los trabajadores que tengan a su cargo y expensas ascendientes (de él o de su cónyuge) que vivan en su compañía, al menos con seis meses de antelación. En el caso de que los ascendientes sean varones, se exige que estos tengan cumplidos sesenta años de edad o se hallen incapacitados para el trabajo.

- Los trabajadores que tengan a su cargo y expensas hermanos (de él o de su cónyuge) menores de catorce años o impedidos para toda actividad que vivan en su compañía, al menos con seis meses de antelación. Para poder percibir el plus por los hermanos a cargo se exige que estos sean huérfanos de padre o que este tenga más de sesenta años o esté incapacitado.

El concepto de hijo se entiende aplicable al que lo sea legítimo, legitimado o adoptivo de cualquiera de los cónyuges. En ningún caso se percibirá el plus por los hijos naturales, aunque estén reconocidos ${ }^{78}$. Los restantes lazos de parentesco (ascendientes o hermanos) habrán de tener siempre un origen legítimo ${ }^{79}$. A efectos del plus se computan

\footnotetext{
76 Salas Montilla, Cristobal, Distribución de los puntos en el plus familiar, ob cit., p. 41-43.

77 Ibidem, p. 47.

78 Resolución DGT 28 de marzo de 1956.

${ }^{79}$ Artículo 8 Orden 29 de marzo de 1946.
} 
como hijos aquellos que, estando a cargo del obrero, reúnan las siguientes características ${ }^{80}$ :

- Hijos solteros y menores de 23 años que no estuvieran trabajando. Se acogió por el legislador una edad superior a la mayoría de edad legal, que a partir de la Ley de 13 de diciembre de $1943^{81}$ era de 21 años.

- Hijos que estuvieran trabajando como aprendices, hasta los 18 años.

- Hijos que, aun siendo mayores de 23 años, se hallen absolutamente incapacitados para todo trabajo.

La delimitación normativa de los beneficiarios del plus familiar evidencia el androcentrismo jurídico del legislador franquista. Toda la regulación pivota sobre la idea de que es el obrero varón del que se espera que sea productor, mientras que a la mujer se la asocia con roles tradicionales extralaborales. Así, y a título ejemplificativo, los ascendientes varones solo se considerarán a cargo si están incapacitados o tienen una edad avanzada, sin que se exijan estas condiciones cuando los ascendientes sean mujeres. En idéntico sentido, los hermanos huérfanos de padre (o con padre incapacitado o de edad avanzada) serán computados como carga, mientras que no tendrán dicha consideración los huérfanos de madre.

\subsection{Reparto del plus: el sistema de puntos}

El fondo del plus que exista en la empresa se repartirá por el sistema de puntos de acuerdo con la siguiente proporción: casados, cuyo cónyuge no trabaje, 5 puntos; casados o viudos con hijos, de 6 a 30 puntos (1 hijo, 6 puntos; 2 hijos, 7 puntos; 3 hijos, 8 puntos; 4 hijos, 10 puntos; 5 hijos, 13 puntos; 6 hijos, 16 puntos; 7 hijos, 19 puntos; 8 hijos, 22 puntos; 9 hijos, 25 puntos; y 10 hijos, 30 puntos). A partir de cada hijo que exceda de diez, se computarán cinco puntos más.

El modelo patriarcal que se adopta en relación con la familia se evidencia en toda su amplitud en el sistema de reparto del plus, que puede ser calificado de antifeminista y pronatalista $^{82}$. Tras este criterio de distribución se puede observar la clara intención del régimen franquista de perpetuar los estereotipos ligados al género. Así, se articula un modelo prestacional que no hace sino buscar la institucionalización de la distribución de

\footnotetext{
${ }^{80}$ Artículo 13 Orden 29 de marzo de 1946.

${ }^{81}$ Ley de 13 de diciembre de 1943 sobre la fijación de la mayoría de edad civil (BOE, 15 de diciembre).

82 VALIENTE FernáNDEZ, Celia, "Olvidando el pasado: la política familiar en España (1975-1996)", Gestión y análisis de políticas públicas, nº 5- 6, 1996, p. 151.
} 
los roles sociales por razón de género. Se busca, directamente y sin ambages, estimular que la mujer se dedique a las labores domésticas y al cuidado de la prole. Además, la propia ordenación del plus promueve un modelo de familia tradicional, basado en el matrimonio católico, y negando derechos a cualquier otra fórmula de organización familiar.

Bajo estas premisas ideológicas, el legislador franquista dibuja y fomenta un arquetipo familiar, considerándolo como el único válido y apto para generar derechos. Las reglas que a continuación se exponen han de ser comprendidas sin perder de vista esta intención legislativa que bajo las mismas subyace:

- Constituye requisito indispensable para que el obrero cobre los puntos por razón de matrimonio que su esposa no trabaje ${ }^{83}$. Se prima, en consecuencia, el salario del beneficiario varón que mantenga económicamente a su esposa ${ }^{84}$. La interpretación de este requisito era muy estricta ${ }^{85}$.

- El plus por matrimonio solo puede ser percibido por la obrera trabajadora en caso de incapacidad del marido o ausencia del mismo, que prive a su familia de toda asistencia económica ${ }^{86}$. Para generar el derecho a favor de la obrera trabajadora, la incapacidad del marido ha de ser total ${ }^{87}$.

- Cuando ambos cónyuges trabajen, percibirá el marido solamente los puntos que correspondan por los hijos que otorguen tal beneficio, salvo que en la actividad en

83 El viudo sin hijos (o con estos que no se computen) percibirá tres puntos (artículo 12 Orden 29 de marzo de 1946).

84 VALIENTE FERnÁNDEZ, Celia, “Olvidando el pasado: la política familiar en España (1975-1996)”, ob cit., p. 154.

85 Entre la extensa casuística existente, se privaba al obrero varón de los puntos del matrimonio si la esposa trabajaba a horas en limpieza (Resolución DGT 16 de marzo de 1956); como portera, incluso cobrando solo en especie por la habitación (Resolución DGT 20 de septiembre de 1954); ayudando en un bar familiar (Resolución DGT 6 de diciembre de 1954); dando clases particulares (Resolución DGT 26 de julio de 1954); o trabajando solo unas horas en domingo (Resolución DGT 21 de junio de 1954).

86 Excepcionalmente, en el sector textil (hilados, tejidos y ramo del agua) de Barcelona y Gerona, la mujer trabajadora podía cobrar el plus familiar por matrimonio aunque su marido trabajara (salvo que también lo hiciera en el mismo sector), percibiendo su esposo trabajador únicamente los puntos que le pudieran corresponder por el resto de familiares a cargo. Vid. Aclaraciones de la Delegación Provincial de Trabajo de Barcelona al régimen de plus de cargas familiares en la industria textil algodonera (BOPB, 22 de septiembre de 1944); Aclaraciones de la Delegación Provincial de Trabajo de Barcelona al régimen de plus de cargas familiares en las industrias textiles (BOPB, 3 de septiembre de 1945); y Resolución de la Delegación Provincial de Trabajo de Gerona modificando las reglas dictadas para la aplicación de los beneficios del plus de cargas familiares (BOPG, 27 de octubre de 1945).

${ }^{87}$ Resolución DGT 24 de octubre de 1955. 
que se ocupe el esposo no existá plus, en cuyo caso hará efectivos la mujer los que correspondan deducidos los cinco de matrimonio. Se aplicará este mismo criterio cuando se encontrare el varón en situación de paro involuntario debidamente justificada. La preferencia de cobro de plus por el marido procede en estos casos aunque la mujer trabajadora tuviera un salario más alto y fuera ella la que mantuviera a la familia, porque el fin del plus no es otro que reincorporar a la mujer casada al ámbito doméstico ${ }^{88}$.

- No habrá derecho a percepción alguna si uno de los cónyuges trabaja por cuenta propia $^{89}$.

- En el caso de separación de hecho, los separados perderán los puntos de matrimonio, conservando los que pudieren corresponderles por los descendientes, ascendientes y hermanos que otorguen derecho a plus. La pérdida de puntos por la separación de hecho no hacía sino fomentar que se silenciara, aún más, esta situación de vida calificada como irregular ${ }^{90}$.

- Si la separación fuera judicial con declaración de cónyuge inocente, este tendrá derecho a percibir los puntos por razón de matrimonio y por los familiares a su cargo, y el culpable tan solo los que pudieran corresponderle por estos últimos, siempre que estuvieren a su cargo. Si la mujer fuese el cónyuge inocente y no trabajase, cobrará el plus en el centro de trabajo donde el marido se encuentre colocado, y, estando empleada, efectuará la percepción allí donde preste sus servicios ${ }^{91}$.

- Los ascendientes o hermanos a cargo tendrán la consideración de hijos a efectos de la obtención de puntos por el trabajador, siempre que este perciba los 5 puntos por matrimonio. En caso contrario, se le computarán solo 3 puntos por familiar a su cargo, y un punto más por cada persona de la familia que, además de la primera, viva a su cargo.

- Cuando conviven varios trabajadores con ascendientes o hermanos a su cargo, solo tendrá derecho a percibir los puntos correspondientes el trabajador casado. Si ninguno lo estuviera o en igualdad de condiciones, la asignación de puntos por

\footnotetext{
${ }^{88}$ Resolución DGT 7 de febrero de 1946.

${ }^{89}$ Artículo 10 Orden 29 de marzo de 1946. Vid. GARCíA OvIEDO, Carlos, Tratado Elemental de Derecho Social ( $6^{\mathrm{a}}$ ed.), ob cit., p. 855.

90 Capella martínez, Miguel y Esteban López-Aranda, Alfonso, Teoría y práctica del plus de cargas familiares, ob cit., p. 44.

${ }^{91}$ Artículo 11 Orden 29 de marzo de 1946.
} 
ascendientes o hermanos a cargo se realizará al trabajador de mayor edad ${ }^{92}$.

La atribución del plus de cargas familiares a cada trabajador beneficiario exige, en primer lugar, determinar el valor del punto. A estos efectos se divide el valor total del fondo del plus empresarial entre el número total de puntos existente en la empresa. Obtenido de este modo el valor del punto, cada trabajador percibirá la cantidad que resulte de multiplicar el valor del punto por los puntos que, según sus circunstancias familiares, tuviera asignados ${ }^{93}$. Los trabajadores con derecho al plus familiar lo harán efectivo sin ningún tipo de limitación respecto al valor del punto ${ }^{94}$.

En el caso de empresas que carezcan de trabajadores con derecho al plus de cargas familiares, el fondo del plus será distribuido entre todos los empleados en proporción a sus sueldos ${ }^{95}$. En estas circunstancias, el plus abandona su naturaleza previsional y se transforma en salario, al perder su finalidad de protección y su condición de complemento del subsidio familiar; o, en otras palabras, deja de ser plus familiar ${ }^{96}$.

El peculiar modelo de reparto del plus implicaba que su importe disminuyera para todos sus perceptores si se incrementaban los empleados con cargas familiares. Así, no era de extrañar que los propios empleados de la empresa se opusieran a la contratación de trabajadores con cargas, ya que, al bajar el valor del punto, les repercutía negativamente en su retribución. De este modo, en no pocas ocasiones los propios trabajadores de la empresa presionaban para que no fueran contratados trabajadores casados o con familia numerosa, pues ello les supondría de facto una rebaja de sus salarios ${ }^{97}$.

\footnotetext{
92 Artículo 9 Orden 29 de marzo de 1946.

93 Artículos 15 y 18 Orden 29 de marzo de 1946.

94 Artículo 27 Orden de 29 de marzo de 1946, modificado por la Orden 16 de octubre de 1952. En la redacción inicial de este precepto se establecía que: "Cuando en razón al escaso número de trabajadores que hayan de disfrutar del Plus o a otras circunstancias el valor del punto sea superior a 30, 45 o 60 pesetas al mes, según que el porcentaje de la nómina destinado al Plus sea el 10, 15 o 20 por ciento, respectivamente, el exceso se distribuirá" entre todos los trabajadores de la empresa en proporción a sus sueldos. Esta limitación del valor del plus familiar quedó suprimida por la Orden de 16 de octubre de 1952.

95 Artículo 26 Orden de 29 de marzo de 1946.

96 PÉREZ BotIJA, Eugenio, "Fundamento jurídico-sociológico del plus familiar", Revista Internacional de Sociología, no 51 (1955), p. 316.

97 GonZÁlez Murillo, Pedro, La política social franquista: el Ministerio de José Antonio Girón de Velasco (1941-1957), Madrid, Universidad Complutense de Madrid (tesis doctoral), 2014, p. 330 (disponible en: https://eprints.ucm.es/id/eprint/26326/1/T22382.pdf, fecha de consulta: 18 de agosto de 2021).
} 


\section{La compleja naturaleza jurídica del plus familiar}

La singular configuración y dinámica del plus de cargas familiares suscitó numerosas dudas interpretativas en su aplicación práctica, estando en la base de todas ellas su conflictiva naturaleza jurídica. En este sentido, se generó un intenso y extenso debate, con indudables consecuencias prácticas, sobre si el plus de cargas familiares debía tener la consideración de salario, o, por el contrario, podía ser entendido como una institución de previsión social encuadrada dentro de los variados y asistemáticos seguros sociales. La discusión dogmática tenía una trascendencia práctica indudable, pues si el plus familiar fuera considerado como salario, las empresas estarían obligadas a abonarlo de forma ordinaria y permanente, debiendo tenerlo en cuenta a efectos de cotización, tributación, indemnización por accidentes de trabajo y enfermedades profesionales y despidos, entre otros aspectos. La doctrina iuslaboralista no resultaba pacífica en este punto. Aunque la postura mayoritaria sostenía que el plus de cargas familiares constituía una institución de previsión social, no faltaban autores que estimaban que dicho plus formaba parte del salario. Ambos posicionamientos se fundamentaban con relativa solidez en distintos argumentos que a continuación se exponen de forma sucinta.

Como se ha apuntado, la mayor parte del iuslaboralismo mantuvo que el plus de cargas familiares encarnaba una institución propia de la previsión social y se encuadraba, en consecuencia, en el incipiente modelo de seguridad social que se estaba pergeñando en el primer franquismo98. Así, el plus familiar se presenta como "un seguro social obligatorio cuyo ámbito de cobertura se restringe a todos y a sólo los que trabajan al servicio de una empresa. El seguro es general en el sentido de que la obligación de aseguramiento se impone a una multiplicidad de empresas y, por tanto, respecto de una multitud de trabajadores, pero es especial o particular en el sentido de que cada empresa forma un núcleo de aseguramiento completamente independiente y distinto de las demás, sin que exista ninguna compensación ni dilución de riesgos entre las mismas" $" 99$. Los argumentos que llevaban a tal convicción se pueden condensar en los siguientes:

- El plus de cargas familiares no se computa para la liquidación de cuotas de los

98 Vid. HeRnAinZ MÁRQUeZ, Miguel, Tratado Elemental de Derecho del Trabajo, ob cit., p. 342 y 373; Alonso OlEA, Manuel, "La Ley de 15 de julio de 1954, por la que se establece la ayuda familiar para funcionarios públicos civiles", ob cit., p. 219; PÉREZ BOTIJA, Eugenio, "Fundamento jurídico-sociológico del plus familiar", ob cit., p. 302 y ss.; y MARTí BUFILL, Carlos, Tratado comparado de Seguridad Social, Madrid, Instituto Nacional de Previsión, 1951, p. 510-513. Este último autor categorizaba el plus dentro de los seguros obligatorios de carácter complementario, junto con el mutualismo laboral obligatorio, el subsidio de paro y el régimen de protección a familias numerosas. Ibidem, p. 498.

99 Alonso Olea, Manuel, Instituciones de Seguridad Social, Madrid, Instituto de Estudios Políticos, 1959, p. 206. 
seguros y subsidios sociales, lo que implica que no pueda ser considerado como salario (artículo 30 Orden de 29 de marzo de 1946).

- El plus familiar obedece a la misma finalidad que el subsidio familiar y, consecuentemente, goza de la misma naturaleza extrasalarial; naturaleza que para el subsidio prevé el legislador expresamente en la Ley de Bases de 18 de julio de 1938, por la que se crea el régimen obligatorio de subsidios familiares, cuando dispone que "el subsidio no es parte del salario, y en consecuencia no será computado a ningún efecto como tal" (Base $\left.3^{\mathrm{a}} .2\right)^{100}$. Al igual que el subsidio, la finalidad del plus es asistencial, de protección social, una ayuda o complemento del salario sin finalidad retributiva ${ }^{101}$. En último término, el plus familiar constituye un complemento del subsidio, "un subsidio del subsidio", un "plus del subsidio"102. El plus tiene su origen en la propia Ley de 18 de julio de 1938 (base 2a ${ }^{\text {a }}$ ), cuando determina que los "subsidios de este régimen legal tienen el carácter de mínimos y pueden suplementarse por las empresas o corporaciones que hayan concedido o concedan otros superiores"103. De este modo, el plus se presenta como una mejora del subsidio que, lógicamente, ha de gozar de su mismo estatus jurídica. Así, si una mejora del subsidio llevada a cabo de forma espontánea por la empresa no desnaturaliza la esencia de la mejora ni la transforma en salario, lo mismo ha de predicarse cuando dicha mejora es impuesta por reglamentación de trabajo o por disposiciones legales ${ }^{104}$.

- Atendiendo a la concepción económica del salario, en cuanto a pago del trabajo prestado, el plus de cargas familiares no podrá tener nunca dicha condición, pues no retribuye de ningún modo el trabajo que se presta, sino que es abonado en atención a la situación familiar del trabajador.

- El plus familiar no puede ser entendido como salario familiar, pues esta institución no tiene cabida en el ámbito del derecho del trabajo al contradecir frontalmente el principio universal "a igual trabajo, igual remuneración”. Además, el salario familiar supone trasladar al empresario problemas personales del trabajador, de los que, en todo caso, se tendría que hacer cargo el Estado a través de políticas públicas

\footnotetext{
100 Vid. artículo 15 Decreto de 20 de octubre de 1938 y artículos 1 y 2 Ley de 17 de julio de 1951 por la que se declara la exención tributaria de subsidio familiar y percepciones complementarias (BOE, 19 de julio).

101 PÉREz BotiJA, Eugenio, “Fundamento jurídico-sociológico del plus familiar”, ob cit., p. 303.

102 Ibidem, p. 312.

103 Vid. artículo 19 Decreto de 20 de octubre de 1938.

104 PÉREZ BotIJA, Eugenio, “Fundamento jurídico-sociológico del plus familiar”, ob cit., p. 311.
} 
adecuadas $^{105}$.

- El plus de cargas familiares hace recaer en una colectividad una carga familiar de tipo personal. El hecho de que la colectividad esté limitada al ámbito de la empresa, no impide que el plus pueda ser considerado como un mecanismo de previsión social, constituyendo en su finalidad y esencia "una manifestación eficaz y sencillamente lograda de la seguridad social"106.

En sentido contrario al expuesto, otro sector de la doctrina mantenía la consideración del plus de cargas familiares como salario con base en los siguientes argumentos ${ }^{107}$ :

- El plus de cargas familiares es concebido por el legislador como un "primer paso al salario familiar". Así, se satisface a los trabajadores "en atención a sus respectivas obligaciones familiares, un plus sobre retribución o emolumentos normales"108.

- El plus de cargas familiares es un aumento del salario del trabajador por motivo de sus cargas familiares, una especie de "supersalario". Ha de entenderse como una clase de salario familiar que pretende ajustar la remuneración del obrero a sus necesidades familiares ${ }^{109}$.

- Que el fondo del plus proceda de las propias empresas y se destine a sus propios trabajadores, sin que se disperse el riesgo a nivel nacional, y que las cuantías sean variables de empresa a empresa, son elementos que alejan al plus de la técnica del seguro social y la acercan a la teoría del salario ${ }^{110}$.

Adoptando una visión sincrética y huyendo de posicionamientos maniqueos, algún autor señala que el plus familiar representa una institución híbrida, en la que concurren elementos que la anudan al salario junto con otros que la ligan a un seguro social de ámbito empresarial ${ }^{111}$.

La discusión doctrinal sobre la naturaleza jurídica del plus familiar se vio reflejada en distintas resoluciones judiciales y administrativas que, principalmente dirigidas a

105 Buenaga Ceballos, Óscar, La familia y la Seguridad Social, ob cit., p. 112.

106 Por todos, Hernainz MárquEZ, Miguel, Tratado Elemental de Derecho del Trabajo, ob cit., p. 373.

107 García OvIEDO, Carlos, Tratado Elemental de Derecho Social (6 $6^{\mathrm{a}}$ ed.), ob cit., p. 851. Cfr. STS, contencioso-administrativo, 16 de mayo de 1955.

108 Exposición de motivos y artículo 1 Orden 29 de marzo de 1946.

109 García Oviedo, Carlos, Tratado Elemental de Derecho Social (6 ${ }^{\mathrm{a}}$ ed.), ob cit., p. 851.

110 Cfr. Buenaga Ceballos, Óscar, La familia y la Seguridad Social, ob cit., p. 118.

111 Almansa PASTOR, José Manuel, Derecho de la Seguridad Social, ob cit., p. 340. 
concretar la dimensión fiscal del plus de cargas familiares, se ocupan de esbozar, en muchas ocasiones de forma poco precisa y contradictoria, la naturaleza jurídica de esta peculiar institución previsional ${ }^{112}$.

El Tribunal Supremo, sala de lo contencioso- administrativo, en su sentencia de 24 de junio de 1952 parece zanjar definitivamente el conflicto. Así, y partiendo de la idéntica finalidad del subsidio familiar y del plus, entiende que esta institución ha de ser considerada como propia de seguridad social, no constituyendo de ningún modo salario las prestaciones que de la misma se derivan y, por tanto, no estando sujeta a imposición. Lejos de lo que cabía esperar, la misma sala del Tribunal Supremo, en su sentencia de 16 de mayo de 1955, modifica su posicionamiento y ordena que el plus familiar se sujete a tributación, al entenderlo como un auténtico salario familiar. Esta interpretación es matizada por el Decreto 1844/1960, de 21 de septiembre, por el que se ordena la retribución del trabajo por cuenta ajena ${ }^{113}$. El artículo 4.1 de esta norma disponía taxativamente que no formaban parte del salario "las prestaciones de carácter familiar". A pesar de esta disposición, el conflicto sobre la naturaleza jurídica del plus familiar siguió plenamente vigente, principalmente por los efectos tributarios que de su calificación se pudieran derivar. En este sentido, el Tribunal Supremo, años después de la entrada en vigor del Decreto 1844/1960, sigue refiriéndose al plus familiar como "remuneración de tipo familiar"114.

\section{A modo de epílogo: cenit y ocaso del plus familiar}

El plus familiar durante sus dos décadas de vigencia gozó de gran popularidad entre la clase obrera. Ello resulta lógico si se tiene en cuenta que el plus suponía para los trabajadores una mejora de sus salarios en una época en la que el incremento de los precios y el coste de la vida hacían que las condiciones de la clase obrera fueran especialmente penosas. A ello, deben añadirse las campañas de adoctrinamiento y propaganda promovidas por el régimen franquista, especialmente intensas en esta materia, y que estaban dirigidas a presentar al plus familiar como una de las grandes realizaciones de política social del nuevo Estado. La valoración que el legislador franquista realizaba del plus lo encumbraba entre sus mayores éxitos, constituyendo un sistema de creación nacional "peculiar que, basado en la solidaridad de los que

112 Especialmente beligerante en este punto se mostró el Ministerio de Hacienda, que, contradiciendo la doctrina del Tribunal Supremo, sujetaba el plus familiar a tributación, asimilándolo al salario y obviando su naturaleza previsional. En este sentido, Alonso OlEA, Manuel, "La Ley de 15 de julio de 1954, por la que se establece la ayuda familiar para funcionarios públicos civiles", ob cit., p. 223. Un completo estudio sobre este punto en ALONSO OLEA, Manuel, "Los gravámenes fiscales de las rentas de trabajo y de las prestaciones de Seguridad Social”, Cuadernos de política social, $\mathrm{n}^{\circ} 22,1954$, p. 53-82.

113 BOE, 11 de octubre de 1960.

${ }^{114}$ STS, 7 de marzo de 1966. 
trabajan unidos en una empresa, cala hondo en las simpatías de trabajadores y empresarios, arraigando definitivamente en el panorama institucional español"115.

Sin embargo, la consideración que el poder político tenía de la institución obviaba muchas de las deficiencias que el plus presentaba. En este sentido, pronto se comenzaron a detectar las inconsistencias internas del plus familiar, que podía conducir a situaciones injustas en su aplicación práctica. Buena parte de la doctrina se mostró muy crítica con la configuración del plus, principalmente por dos motivos ${ }^{116}$.

En primer lugar, la duplicidad del sistema de protección familiar era considerada como una anomalía del modelo previsional que mermaba la eficiencia de su finalidad protectora. La existencia de dos instituciones de seguridad social dirigidas a una misma finalidad carecía de sentido, suponiendo una dualidad injustificada que perjudicaba, en último término, al objeto de protección. En este sentido, resultaba más recomendable conformar una única institución de protección familiar pública que cohonestara los aspectos más positivos de los subsidios familiares y del plus, corrigiendo las deficiencias que la aplicación de ambas instituciones había puesto de manifiesto durante los primeros años de su vigencia ${ }^{117}$.

En segundo lugar, el plus familiar generaba en su aplicación unas diferencias injustificables entre empresas, e incluso entre empresas de la misma actividad. El importe del plus dependía de numerosas variables: sector de actividad, nivel salarial de la empresa y nivel de trabajadores con cargas. Al variar el alcance del plus en función del número de trabajadores con cargas familiares que tuviera cada empresa, se suscitaban problemas de colocación para los trabajadores con mayor número de obligaciones familiares. De este modo, lo que en principio está dirigido a ayudar a la familia, se convierte en la práctica en un mecanismo de exclusión laboral de aquellos trabajadores con mayores cargas y en un instrumento de generación de "desigualdades

115 Exposición de motivos Ley 1/1962, de 14 de abril, sobre Régimen Laboral de Ayuda Familia (BOE, 16 de abril de 1962).

116 Capella Martínez, Miguel y Esteban LóPez-Aranda, Alfonso, Teoría y práctica del plus de cargas familiares, ob cit., p. 6 y ss.

117 Cfr. Fagohaga G.-Solana, Miguel, "La protección a la familia en la Ley de Bases de la Seguridad Social”, Revista de Política Social, $\mathrm{n}^{\circ}$ 61, 1964, p. 242 y 243. Ilustrativa resulta a estos efectos la exposición de motivos de la Ley 1/1962, de 14 de abril, sobre Régimen Laboral de Ayuda Familia, que señala literalmente: "tanto el subsidio como el plus tienen el mismo origen, se proponen idénticas finalidades y se nutren del mismo sector de la renta nacional, por lo que nada esencial justifica la actual separación, con su consiguiente secuela de gastos y esfuerzos innecesarios y desigualdad en los beneficios percibidos y en las aportaciones exigidas". Con todo, no faltan autores coetáneos que sostienen que el subsidio y el plus familiar obedecen a distintas causas, no resultando recomendable su unificación en una única institución. Vid. SALAS MonTILla, Cristóbal, Distribución de los puntos en el plus familiar, ob cit., p. 6 y 7. 
irritantes"118.

Las críticas al plus familiar se fueron reproduciendo exponencialmente en la medida en que se operaba un cambio social en España generado principalmente por el desarrollo económico de los años sesenta. El desarrollo económico, la concentración urbana, el incremento de las tasas de escolarización, el aumento del trabajo extradoméstico de la mujer y la reducción del paro, fueron algunos de los elementos que determinaron el tránsito de "una sociedad de familias a una sociedad de individuos"119. El cambio social descrito provocó que el plus familiar se presentara como una institución anacrónica y desfasada en atención a la nueva realidad socioeconómica que emergía en los inicios de la década de los sesenta en España.

Con el fin de resolver estos y otros problemas, se dicta la Ley 1/1962, de 14 de abril, sobre Régimen Laboral de Ayuda Familiar; norma que unifica el sistema de protección familiar de seguridad social, pero que no pudo ser aplicada en la práctica al ser suspendida por Decreto-ley 2/1963, de 17 de enero, sobre Régimen de Ayuda Familiar ${ }^{120}$. Esta última disposición remitía la definitiva ordenación de las prestaciones familiares a una inminente regulación, que se vería materializada poco después en la Ley 193/1963, de 28 de diciembre, sobre Bases de la Seguridad Social, y que ponía fin a dos décadas de plus familiar en España.

\section{Bibliografía}

Almansa Pastor, José Manuel, Derecho de la Seguridad Social, Madrid, Tecnos, 1973.

Alonso García, Manuel, Política social española en relación con la familia, Madrid, Ediciones del Congreso de la Familia Española, 1958.

Alonso OleA, Manuel, Instituciones de Seguridad Social, Madrid, Instituto de Estudios Políticos, 1959.

Alonso Olea, Manuel, Instituciones de Seguridad Social, Madrid, Civitas, 1983, $9^{\mathrm{a}}$ ed.

Alonso OleA, Manuel, "La Ley de 15 de julio de 1954, por la que se establece la ayuda familiar para funcionarios públicos civiles", Revista de Administración Pública,

118 Fagoaga G. SolanA, Miguel, "La protección a la familia en la Ley de Bases de la Seguridad Social", ob cit., p. 244.

119 IGLESIAS DE USSEL, Julio, "La familia y el cambio político en España”, ob cit., p. 243.

${ }^{120}$ BOE, 18 de enero de 1963. 
$\mathrm{n}^{\mathrm{o}} 14,1954$.

Alonso OlEA, Manuel, "La Seguridad Social: presente, pasado y futuro", en GonZALO González, Bernardo y Nogueira Gustavino, Magdalena (Directores), Cien Años de Seguridad Social, UNED y Fraternidad Muprespa, Madrid, 2000.

Alonso OlEA, Manuel, "Los gravámenes fiscales de las rentas de trabajo y de las prestaciones de Seguridad Social”, Cuadernos de política social, n 22, 1954.

AZNAR, Severino, Del salario familiar al seguro familiar (evolución de una ideafuerza), Santander, Ministerio de Organización y Acción Sindical, 1939, $3^{\text {a }}$ ed.

AZPIAZU, Joaquín, Orientaciones cristinas del Fuero del Trabajo, Burgos, Imprenta Aldecoa, 1939.

Blasco LaHOZ, José Francisco y LóPez Gandía, Juan, Curso de Seguridad Social, Valencia, Tirant lo Blanch, 2016, $6^{\mathrm{a}}$ ed.

Buenaga Ceballos, Óscar, La familia y la Seguridad Social, Madrid, Dykinson, 2014.

Capella Martínez, Miguel y Esteban LóPEZ-Aranda, Alfonso, Teoría y práctica del plus de cargas familiares, Madrid, Gráficas Sigma, 1946.

CARASA Soto, Pedro, "La revolución nacional-asistencial durante el primer franquismo (1936-1940)”, Historia Contemporánea, nº 16, 1997.

Casanova Ruiz, Julián, La Iglesia de Franco, Barcelona, Crítica, 2005.

Collantes de Terán De la Hera, María José, "La política social en el nuevo Estado Franquista: protección a las familias numerosas", en ALEJANDRE GARCÍA, Juan Antonio (Coordinador), Estudios jurídicos sobre el franquismo. La familia ideal y otras cuestiones, Madrid, Dykinson, 2009.

Comín y Comín, Francisco, "Las fases históricas de la Seguridad Social en la España del siglo XX”, en Tortuero PlazA, José Luís (Director), Cien años de Protección Social en España, Ministerio de Trabajo y Asuntos Sociales, Madrid, 2007.

Comín y Comín, Francisco, "Las fases históricas de la Seguridad Social en España (1900-2000)”, Revista de Historia de la Economía y de la Empresa, no 4, 2007. 
DE LA VILLA GIL, Luis Enrique, "El Derecho del Trabajo en España a partir de la transición”, Revista de Trabajo y Seguridad Social, n 238, 2003.

De la VILla GIL, Luis Enrique, La formación histórica del Derecho Español del Trabajo, Granada Comares, 2003.

ESPUNY TOMÁs, María Jesús, “Aproximación histórica al principio de igualdad de sexos (IV): De la Ley de Contrato de Trabajo de 1944 a las últimas disposiciones franquistas", IUSLabor, $\mathrm{n}^{\circ}$ 1, 2008.

Fagoaga G.-Solana, Miguel, "El plus familiar y el impuesto de utilidades", Cuadernos de Política Social, nº 15, 1952.

Fagohga G.-Solana, Miguel, "La protección a la familia en la Ley de Bases de la Seguridad Social", Revista de Política Social, nº 61, 1964.

FERnÁNDEZ HerAs, Amado, Aplicación general del plus de cargas familiares en la industria y el comercio, Zaragoza, Tip. La Editorial, 1945.

FERNÁNDEZ HERAS, Amado, Normas únicas para aplicación del plus familiar, Zaragoza, La Editorial Lasala y Cía., 1956, $12^{\text {a }}$ ed.

FRANCO RUBIO, Gloria, "De la vida doméstica a la presencia pública: las mujeres en las cortes franquistas”, en PÉREZ CANTÓ, Pilar (ed.), De la democracia ateniense a la democracia paritaria, Barcelona, Icaria Editorial, 2009.

García Oviedo, Carlos, Tratado Elemental de Derecho Social, Sevilla, Librería General de Victoriano Suárez, 1946.

García OviEdo, Carlos, Tratado Elemental de Derecho Social, Madrid, EISA, 1954, $6{ }^{\text {a }}$ ed.

GonZÁlez Murillo, Pedro, La política social franquista: el Ministerio de José Antonio Girón de Velasco (1941-1957), Madrid, Universidad Complutense de Madrid (tesis doctoral), 2014 (disponible en: https://eprints.ucm.es/id/eprint/26326/1/T22382.pdf).

GonzÁlez-Posada Martínez, Elías, El Derecho del Trabajo. Una Reflexión sobre su evolución histórica, Valladolid, Universidad de Valladolid, 1996.

GORELli HeRnÁNDEZ, Juan, “Seguridad Social y protección familiar”, Revista del 
Ministerio de Trabajo y Asuntos Sociales, nº 59, 2005.

Hernainz MÁRquez, Miguel, Tratado Elemental de Derecho del Trabajo, Madrid, Instituto de Estudios Políticos, 1961, $8^{\mathrm{a}}$ ed.

IGLESIAS DE USSEL, Julio, "La familia y el cambio político en España", Revista de Estudios Políticos, nº 67, 1990.

IGLESIAS DE UsSel, Julio, "La protección de la familia en España", Papeles de Economía Española, no 77, 1998.

IGLESIAS DE USSEL, Julio y FLAQUER, Lluis, "Familia y análisis sociológico: el caso de España”, Revista Española de Investigaciones Sociológicas, nº 61, 1993.

MANRIQUe ARRIBAS, Juan Carlos, "La familia como medio de inclusión de la mujer en la sociedad franquista", Hispania Nova. Revista de Historia Contemporánea, n 7, 2007.

Martí Bufill, Carlos, Tratado comparado de Seguridad Social, Madrid, Instituto Nacional de Previsión, 1951.

MARTÍNEZ GiRÓN, Jesús, "La etapa de previsión social en España", Anuario da Facultade de Dereito da Universidade da Coruña, $\mathrm{n}^{\circ}$ 5, 2001.

Molinero, Carme, "Falange y la construcción del régimen, 1939-1945. La búsqueda de unas bases sociales”, en RUIZ CARNICER, Miguel Ángel (Coordinador), Falange, las culturas políticas del fascismo en la España de Franco (1936-1975) (vol. I), Zaragoza, Institución Fernando el Católico, 2013.

Montoya Melgar, Alfredo, "El Instituto Nacional de Previsión, fundamento de la protección social española", en TORTUERo PlaZA, José Luis (Director), Cien años de Protección Social en España, Ministerio de Trabajo y Asuntos Sociales, Madrid, 2007.

Montoya Melgar, Alfredo, La representación sindical en la empresa, Sevilla, Instituto García Oviedo- Universidad de Sevilla, 1968.

Pallás-Vilaltella, Francisco, La doctrina social de la Iglesia sobre la condición y el trabajo de los obreros, Madrid, Espasa-Calpe, 1941.

PÉREZ BotiJA, Eugenio, "Fundamento jurídico-sociológico del plus familiar", Revista Internacional de Sociología, $\mathrm{n}^{\circ}$ 51, 1955. 
Purcalla Bonilla, Miguel Ángel y JordÀ FernándeZ, Antoni, Las relaciones laborales en España hasta la Constitución de 1978, Madrid, Dykinson, 2007.

RAMíRez MARTíneZ, Juan Manuel (Director), Curso de Derecho del Trabajo, Valencia, Tirant lo Blanch, 2003, $12^{\mathrm{a}}$ ed.

Roca i GiRonA, Jordi, "Esposa y madre a la vez. Construcción y negociación del modelo ideal de mujer bajo el (primer) franquismo", en NIELFA CRISTÓBAL, Gloria (ed.), Mujeres y hombres en la España franquista: sociedad, economía, política y cultura, Madrid, Editorial Complutense, 2003.

RUIz Rico, Juan José, El papel político de la Iglesia Católica en la España de Franco, Madrid, Tecnos, 1977.

Salas Montilla, Cristóbal, Distribución de los puntos en el plus familiar, Barcelona, Casa Provincial de Caridad, 1955, $5^{\text {a }}$ ed.

VALIENTE FERNÁNDEZ, Celia, "Olvidando el pasado: la política familiar en España (1975-1996)”, Gestión y análisis de políticas públicas, no 5- 6, 1996.

VILlar Palasí, José Luis y MuÑoz CAMPos, Juan, Jurados de Empresa, Madrid, SIPS DNS, 1950. 